\title{
War of the Worlds Revisited: The Effect of Watching "The Day After" on Mood State
}

\author{
David G. Daniel, MD \\ Vanderbilt University Medical Center \\ Frances Wolff, M.Ed. \\ Tufts University \\ Maribeth Smith, MA \\ Vanderbilt University
}

Follow this and additional works at: https://jdc.jefferson.edu/jeffjpsychiatry

Part of the Psychiatry Commons

Let us know how access to this document benefits you

\section{Recommended Citation}

Daniel, MD, David G.; Wolff, M.Ed., Frances; and Smith, MA, Maribeth (1987) "War of the Worlds Revisited: The Effect of Watching "The Day After" on Mood State," Jefferson Journal of Psychiatry. Vol. 5 : Iss. 2 , Article 8.

DOI: https://doi.org/10.29046/JJP.005.2.005

Available at: https://jdc.jefferson.edu/jeffjpsychiatry/vol5/iss2/8

This Article is brought to you for free and open access by the Jefferson Digital Commons. The Jefferson Digital Commons is a service of Thomas Jefferson University's Center for Teaching and Learning (CTL). The Commons is a showcase for Jefferson books and journals, peer-reviewed scholarly publications, unique historical collections from the University archives, and teaching tools. The Jefferson Digital Commons allows researchers and interested readers anywhere in the world to learn about and keep up to date with Jefferson scholarship. This article has been accepted for inclusion in Jefferson Journal of Psychiatry by an authorized administrator of the Jefferson Digital Commons. For more information, please contact: JeffersonDigitalCommons@jefferson.edu. 


\title{
War of the Worlds Revisited: The Effect of Watching "The Day After" on Mood State
}

\author{
David G. Daniel, M.D. \\ Frances Wolff, M.Ed. \\ Maribeth Smith, M.A.
}

\section{INTRODUCTION}

In the fall of 1983, "The Day After," a fictional account of a nuclear attack on a civilian population, was broadcast on television in the United States and viewed by 100 million Americans. "The Day After" was said to differ from previous movie treatments of nuclear war by the vividness with which it forced its audience to experience the ground zero effects of a nuclear blast on human beings (1). In what was described as "the most horrifically searing footage ever to pass a network censor," the audience was shown "group immolation, a carnage of mass vaporization" and "graphic images of death" (1). It was widely predicted that this movie would have stressful psychological effects because it dealt with a potentially real disaster. Warnings of possible psychiatric side effects of the film were issued by the American Psychiatric Association, the American Academy of Child Psychiatry, the American Academy of Pediatrics, and the American Broadcasting Company $(1,2,3)$. So seriously were these warnings taken that the Federal Emergency Management Agency increased its staffing in anticipation of the movie's psychological fallout (2). After the movie was shown, however, there was little systematic documentation of its psychological effects on the public. Since similarly graphic movies addressing the effects of nuclear war continue to be released and are planned for the future, we feel the issue of the psychological effects of these films remains salient.

In order to stimulate interest in survey methods of assessing the psychiatric effects of media events, we conducted a study in which we administered the State-Anxiety (A-State) subscale of the State-Trait Anxiety Inventory (STAI) and the Multiple Affect Adjective Check List (MAACL) to 37 subjects immediately before and after they watched "The Day After." The results of this study

David Daniel, M.D. was Chief Resident in Psychiatry at Vanderbilt University Medical Center, Nashville, Tennessee, when this paper was written. Currently, Dr. Daniel is continuing his training at the Clinical Brain Disorders Branch of the Intramural Research Program of the NIMH as a Medical Staff Fellow.

Frances Wolff, M.Ed. received her Masters of Education in Counseling Psychology from Tufts University in 1982.

Maribeth Smith, M.A. is a doctoral candidate in the Vanderbilt University Department of Psychology. 
are reported and discussed in the context of similar data attained from studies of the effects of more conventional movies depicting violence or bloodshed.

\section{METHOD}

Subjects

In order to minimize selection bias and increase the size of the sample, subjects were recruited from three different sources. Of these, two were group settings in which the public was invited by posted notices to view the movie at a Unitarian Church $(n=19)$ and at a medical school classroom $(n=9)$. The third set of subjects were volunteers who viewed the movie privately in their homes $(\mathrm{n}=9)$.

The ages of the combined sample $(n=37)$ ranged from 15 to 47 years with a median age of 32 years. Nineteen subjects were female, 16 were male and 2 subjects declined to identify their sex. The group was highly educated as a whole, with 34 subjects having had at least some college. Thirteen subjects reported activity in nuclear war consciousness-raising groups; this proportion was self-selected by responding to the notices.

Participants filled out a questionnaire eliciting demographic information and their degree of participation in nuclear war consciousness-raising groups, and completed two self-report measures of affective state immediately before and then after viewing the movie. The subjects who viewed the movie in the group settings were administered the questionnaires by the first author or a research assistant. The subjects who viewed the movie in their homes were instructed to complete the questionnaire individually and not to discuss the results until they had completed the entire study. One subject dropped out of the study after writing "drained" on his questionnaire. For the final stage of the study, all subjects were instructed to complete the MAACL and A-State in private, at home, at 8 p.m. 72 hours after having viewed the movie. A preaddressed, stamped envelope was provided for return of the questionnaire. Nineteen subjects completed this last set of questionnaires in the final stage of the study. The reasons why the remaining 18 dropped out were not ascertainable.

Measures

Measures included the Multiple Affect Adjective Check List (MAACL) and the State-Anxiety subscale (A-State) of the State-Trait Anxiety Inventory. The MAACL is a brief, self-administered test designed to provide valid measures of anxiety, depression and hostility (4). The standard instructions of the "Today Form" were used, which direct the subject to describe how they feel "now." The second measure, the A-State of the State-Trait Anxiety Inventory, consists of 20 statements which allow subjects to indicate how they feel at a particular moment in time (5). These measures were chosen because extensive use has attested to their validity, and because they have been used in previous studies of movies' 
effects. The third measure, which was created for this study, is a Likert-like scale ranging from 1 (no activity) to 10 (extremely active) on which the subjects indicated their degree of participation in nuclear war consciousness-raising groups.

Mean pre-film, mean post-film, and mean post-film minus pre-film scores were calculated for the A-State and the three MAACL subscales. Using analysis of various (ANOVA, using the SPSS program) for unweighted means, there were no significant differences between the three sample subgroups on any of these measures. Therefore, for all subsequent analyses the three sample subgroups were combined to provide $n=37$.

\section{FINDINGS}

As illustrated in Table 1, two-tailed T-tests revealed no significant relationship between the changes in A-State and MAACL scores produced by watching the movie and the subjects' degree of participation in nuclear war consciousnessraising groups. That is, after watching the movie, the subjects' anxiety, hostility and depression as measured by the A-State and MAACL did not increase significantly more in nuclear activists than in others. As seen in Table 2, analysis of variance (ANOVA) revealed no significant relationship between the subjects' sex and the effects of the movie on A-State and MAACL scores. However, for the MAACL-Anxiety measure, analysis of variance suggested that females' pre-film anxiety was significantly higher than that of males. Table 3 shows that Pearson correlation coefficients revealed no significant relationship between age and any of the affective measures.

A statistical comparison (ANOVA) of the mean pre-film and post-film scores for the A-State and MAACL scales is summarized in Table 4. Analysis of variance revealed a significant increase in the subjects' mean affective scores on

TABLE 1.

Relationship of Participation in Nuclear War Consciousness Raising Groups to Affect Induced by Watching "The Day After"

\begin{tabular}{lcccc}
\hline \multicolumn{1}{c}{ Measure } & T value* & df & $\begin{array}{c}(\Omega \\
\downarrow)\end{array}$ & $\begin{array}{c}\text { Two-tail } \\
\text { prob }\end{array}$ \\
\hline $\begin{array}{l}\text { Change in A-State } \\
\text { (STAI) Score }\end{array}$ & 0.76 & 24 & 26 & NS \\
$\begin{array}{l}\text { Change in MAACL } \\
\begin{array}{l}\text { Anxiety Score } \\
\text { Change in MAACL }\end{array}\end{array}$ & 1.25 & 27 & 29 & NS \\
$\begin{array}{l}\text { Depression Score } \\
\text { Change in MAACL }\end{array}$ & 0.91 & 27 & 29 & NS \\
Hostility Score & 1.35 & 27 & 29 & NS \\
\hline
\end{tabular}

*For purposes of this analysis, subjects were divided into two groups defined by whether the subject had some or no participation in nuclear war consciousness-raising groups. 
TABLE 2.

Relationship of Affective Measures to Sex

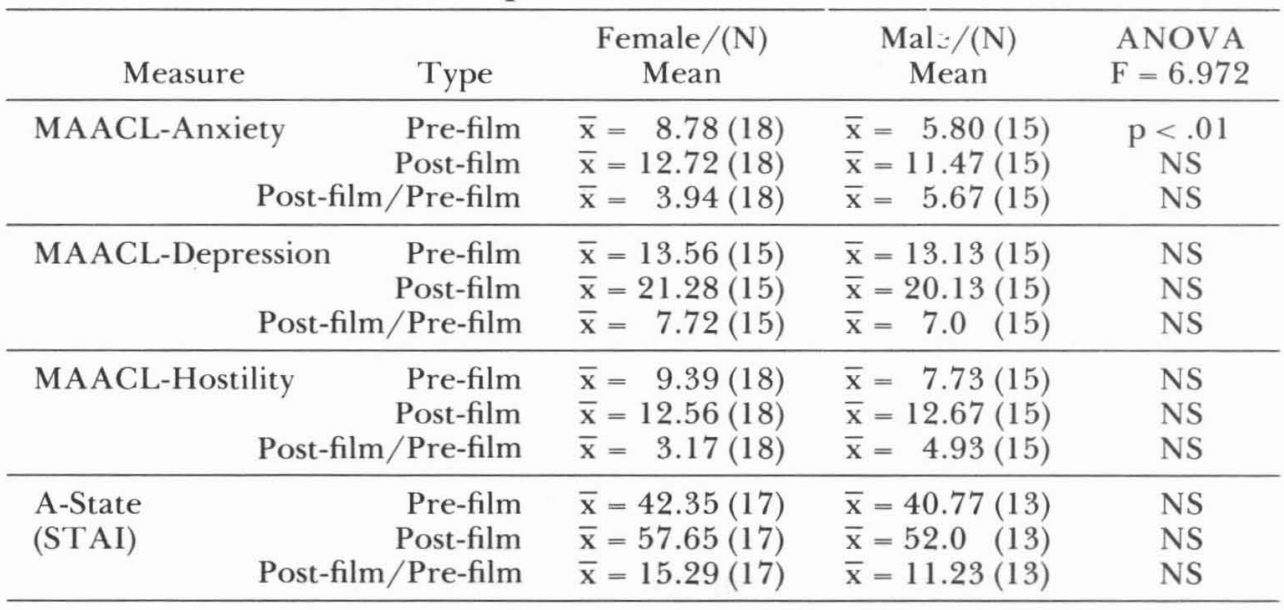

each measure after watching the film. The mean A-State score increased from 40.90 immediately prior to the movie to 54.73 immediately afterwards $(\mathrm{p}<.001)$. In 28 subjects A-State scores increased after the movie (range: +1 to +39 ) while in four subjects they decreased (range: -1 to -28 ). MAACLAnxiety scores increased from a mean of 7.00 immediately prior to the movie to a mean of 11.80 immediately after $(\mathrm{p}<.001)$. MAACL-Anxiety scores increased in 28 (range: +1 to +15 ).

TABLE 3.

Relationship of Affective Measures to Age

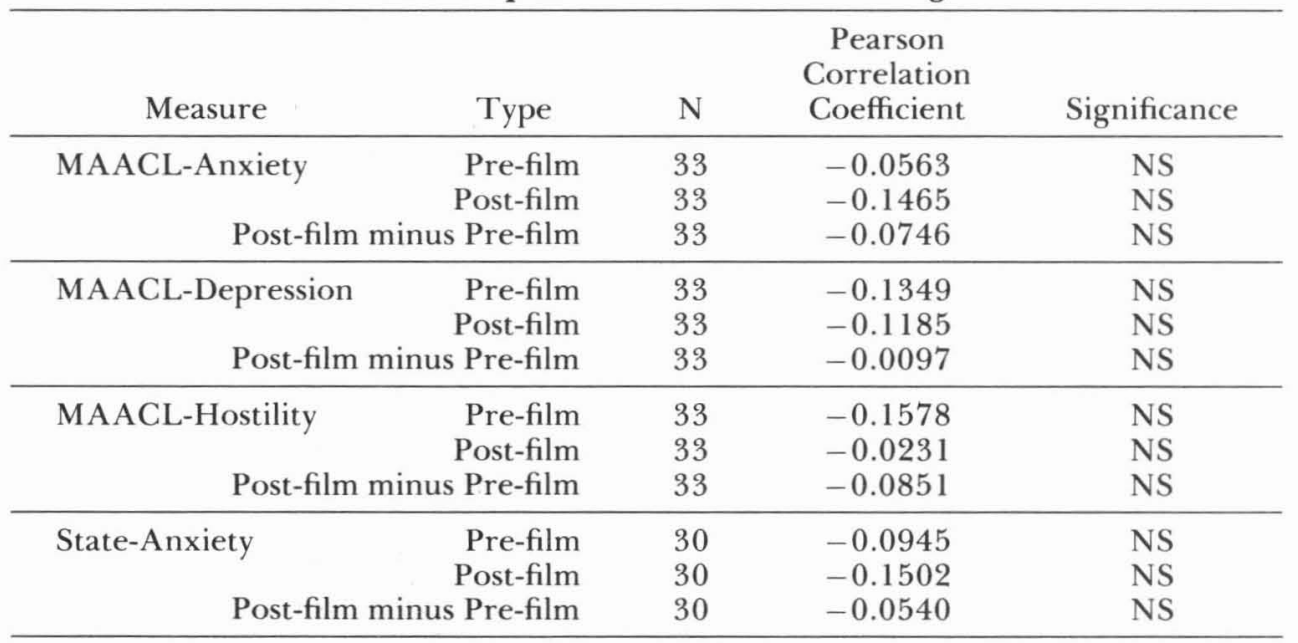


TABLE 4.

Comparison of Affective Measures Before and After Watching "The Day After"

\begin{tabular}{lcccc}
\hline & MAACL & MAACL & MAACL & Anxiety \\
Hostility & Depression & $\begin{array}{c}\text { STAI } \\
\text { State-Anxiety }\end{array}$ \\
\hline Mean Score Pre-film & $\overline{\mathrm{x}}=8.01$ & $\overline{\mathrm{x}}=7.00$ & $\overline{\mathrm{x}}=12.32$ & $\overline{\mathrm{x}}=40.90$ \\
Mean Score Post-film & $\overline{\mathrm{x}}=12.57$ & $\overline{\mathrm{x}}=11.88$ & $\overline{\mathrm{x}}=20.55$ & $\overline{\mathrm{x}}=54.73$ \\
$\mathrm{~N}$ & 35 & 35 & 35 & 32 \\
$\mathrm{p}^{*}$ & $<.001$ & $<.001$ & $<.001$ & $<.001$ \\
\hline
\end{tabular}

*One way Analysis of Variance (ANOVA) with repeated measures; unweighted means.

\section{DISCUSSION}

A comparison of affective states before and after watching the movie "The Day After" revealed statistically significant increases in anxiety, depression, and hostility scores as measured by the MAACL and STAI A-State. It is reassuring that in the subset that was retested 72 hours later, MAACL and STAI A-State scores had essentially returned to baseline. However, it cannot be stated definitively that this subset was representative of the original sample as a whole. The use of the MAACL and STAI to measure mood changes produced by movies has precedents in the works of Zuckerman, Luben, Vogel et al (4), and of Lazarus and Opton (5), respectively. Although direct statistical comparison of their findings to ours was not possible, their results provide a context in which to view the results of the current study.

Zuckerman's group administered the MAACL to 34 college students before and after they were shown "The Blood of the Beasts," a vivid, detailed account of procedures in a slaughter house. The mean change in MAACLDepression scores for the males in Zuckerman's group after watching this film was $+4.53(n=15)$ compared to a change of $+7.00(n=15)$ for the males in our group after watching "The Day After." For the females in Zuckerman's sample,

\section{TABLE 5 .}

Affective Measures Before, Immediately After and 72 Hours After Watching "The Day After"

\begin{tabular}{lcccc}
\hline & $\begin{array}{c}\text { MAACL } \\
\text { Hostility }\end{array}$ & $\begin{array}{c}\text { MAACL } \\
\text { Anxiety }\end{array}$ & $\begin{array}{c}\text { MAACL } \\
\text { Depression }\end{array}$ & $\begin{array}{c}\text { STAI } \\
\text { State-Anxiety }\end{array}$ \\
\hline $\begin{array}{l}\text { Mean Score Pre-film } \\
\text { Mean Score Immediately }\end{array}$ & $\overline{\mathrm{x}}=9.31$ & $\overline{\mathrm{x}}=10.08$ & $\overline{\mathrm{x}}=15.85$ & $\overline{\mathrm{x}}=43.75$ \\
$\begin{array}{l}\text { Post-film } \\
\text { Mean Score 72 hours }\end{array}$ & $\overline{\mathrm{x}}=13.23$ & $\overline{\mathrm{x}}=12.85$ & $\overline{\mathrm{x}}=20.08$ & $\overline{\mathrm{x}}=55.50$ \\
$\begin{array}{l}\text { Post-film } \\
\text { N }\end{array}$ & $\overline{\mathrm{x}}=10.46$ & $\overline{\mathrm{x}}=7.23$ & $\overline{\mathrm{x}}=14.77$ & $\overline{\mathrm{x}}=42.17$ \\
p* & 19 & 19 & 19 & 19 \\
& NS & NS & NS & NS \\
\hline
\end{tabular}

*One way Analysis of Variance (ANOVA) with repeated measures; unweighted means. 
the mean change in MAACL-Depression scores was $+5.47(n=18)$ after watching "The Blood of the Beasts" compared to a change of $+7.92(n=15)$ for the females in our group after watching "The Day After."

Lazarus and Opton (5), administered the STAI A-State scale to 197 undergraduates under a "normal" and a "movie" condition depicting accidents in a woodworking shop. For the males in Lazarus' study the mean A-State score changed $+14.04(\mathrm{n}=100)$ after watching the woodworking accident movie, compared to a mean change of $+11.23(n=13)$ in our males after watching "The Day After." The mean A-State score of the females in Lazarus' group increased by $+15.29(\mathrm{n}=88)$ after they watched the woodworking accident movie, compared to a mean increase of $+11.23(n=17)$ for the females in our group after they watched "The Day After."

It would surprise few people that a movie graphically depicting nuclear destruction of a human population would produce considerably more depressed affect than would Zuckerman's movie depicting the slaughter of animals. That is, intuitively, one would expect people to identify more with human victims of violence than with non-human victims. On the other hand, it would have been harder to predict that Lazarus and Opton's movie depicting accidents in a woodworking shop would be more anxiety provoking than a movie depicting the destruction of the world as we know it. It could be that relatively greater use of ego defenses such as denial are induced by the massive specter of catastrophe presented by “'The Day After” than by woodworking shop accidents. Or it could be that woodworking accidents seemed like more realistic and germane concerns in the subjects' everyday world than did the specter of nuclear war, and thus produce more anxiety.

One of the reasons given for the great concern expressed over the potential adverse psychological effects of movies like "The Day After" are the huge sizes (i.e., 100 million viewers) of the audiences that watch the films at the same time. In our sample, the film produced statistically significant increases in anxiety, depression, and hostility as measured by the MAACL and STAI A-State. No one can say for sure what the psychological, sociological and political repercussions of a simultaneous mood change cathected to a common theme in so many people might be. Unlike the chaos created by "The War of the Worlds," "The Day After" resulted in no mass hysteria or panic. The reasons for the difference may be that the publicity preceding the showing of "The Day After," along with the show's format and breaks for advertisements left no room for doubt in even the most isolated, naive or suggestible viewers about the movie's fictional character. The hype preceding the showing of "The Day After" allowed viewers to psychologically prepare themselves for what they were going to see without being as surprised or shocked as they might have been without such prior preparation.

The effects on affect of watching “The Day After" were not related to age, sex, or degree of nuclear-related issues activism in a statistically significant way. On the face of it, the latter finding may seem counterintuitive. That is, one 
might reasonably hypothesize that persons politically active in this area would be more emotionally invested in the subject matter and react to a movie about nuclear war with more affect. It would seem naive, however, to assume that nuclear war activists are a homogeneous group that react in the same way emotionally when confronted with images of nuclear war. Nuclear war activists could be expected to have had more experience dealing with the issue than the average viewer, and therefore to be better prepared emotionally. It is also likely that there would be wide variability in the ego defenses employed when watching the movie, which would further contribute to the heterogeneity of the nuclear war activists' response.

In summary, this study suggests that media events such as "The Day After" may produce significant acute, but probably temporary, measurable mood changes (including hostility, depression, and anxiety) in viewers. The purpose of this study was to stimulate interest in survey methods of documenting the induction of emotional states by such films. For programs such as "The Day After" which may have simultaneous audiences of 100 million viewers or more, the psychiatric, sociological, and political impact of such mood changes deserve further exploration and documentation.

\section{REFERENCES}

1. Waters HF, Karlen N, Doherty S, et al: Television's nuclear nightmare. Newsweek: November 21, 1983, pp 66-72

2. Morganthaw T: After “The Day After" Newsweek: December 5, 1983, p 62

3. Schofield J and Povelchak M: "The Day After," The impact of a media event. American Psychologist 40(5):542-548

4. Zuckerman M, Lubin B, Vogel L, et al: Measurement of experimentally induced affects. Journal of Consulting Psychiatry 28(5):418-425, 1964

5. Spielberger CD, Gorsuch RL, Lushene RE: State-Trait Anxiety Inventory. Preliminary test manual for Form X. Tallahassee, Florida, Florida State University, 1986 